\title{
O FATALismo ReLATIVÍSTICo
}

\author{
RELATIVISTIC FATALISM \\ ELton Martins Marques \\ Universidade Federal do Rio de Janeiro, CNPq Grant, BRASIL \\ Centro de Filosofia da Universidade de Lisboa, LanCog Group, PORTUGAL \\ eltonmarques@campus.ul.pt
}

\begin{abstract}
In this article, I will argue that the argument for fatalism based on the relativity of simultaneity (RoS) fails. The original proponents of the argument (Rietdijk 1966, Putnam 1967 and Penrose 1989) called the thesis in terms of 'determinism', but Levin (Levin 2007) refers to it as 'relativistic fatalism'. Relativistic fatalism is a view supported by the alleged dependence of the property of being future on an arbitrary choice of some coordinate system. First I will try to explain the classic argument, attributed to it a dialectic that justified to call it in the same terms as Levin did. Subsequently, I will refuse the relativistic fatalism using many strategies to deal with it.
\end{abstract}

Keywords: Determinism $\bullet$ fatalism $\bullet$ relativity of simultaneity $\bullet$ Ockhamism $\bullet$ non sequitur

\section{Introdução}

Um argumento por Rietdijk, Putnam e Penrose é algumas vezes classificado como fatalista, apesar dos autores o mencionarem como determinista. Segundo Levin, a tese por esse argumento pretendida pode ser chamada de "fatalismo relativístico" (Levin 2007, p.433). Inicialmente, iremos nos concentrar na tese enunciada nesses termos, explicando as razões para considerar essa formulação adequada. Depois tentaremos, baseados na tese segundo a qual o fatalismo lógico é uma proposta cujo equívoco é identificável, evitar o fatalismo relativístico, após considerações sobre as semelhanças entre o fatalismo relativístico e o fatalismo em geral.

Na secção a seguir, tentaremos localizar, no argumento dos autores acima, a dialética que os torna semelhantes. A nossa intenção será mostrar como a mesma pode ser útil para quem estiver interessado em fundamentar o fatalismo. Após esse passo, nas secções seguintes, iremos recusar o fatalismo relativístico em diferentes versões.

\section{A dialética do argumento}

O argumento que será estudado neste artigo foi postulado pela primeira vez por Rietdijk (Rietdijk 1966) e Putnam (Putnam 1967), sendo então seguido por Penrose 
(Penrose, 1989) e muitos outros. ${ }^{1}$ O nosso objetivo não será apresentar as diferentes versões que o argumento tem. Ao invés disso, iremos nos concentrar na exposição daquilo que seria a dialética comum que perpassa toda a argumentação, mesmo nas diferentes versões, para então recusá-lo.

Inspirado pela relatividade da simultaneidade, esse argumento providencia uma premissa fundamental para a construção de um antigo argumento lógico-semântico (cf. Aristóteles 1963). Na versão de Aristóteles, sobre a qual há diferentes interpretações, há certa incompatibilidade entre o princípio da bivalência ${ }^{2}$ e a contingência para fatos futuros. As seguintes passagens podem ser usadas para esclarecer o cerne do argumento aristotélico: "Pois se é verdadeiro dizer que é branco ou não branco, é necessário ser Branco ou não Branco ..." (Aristóteles 1984, 18 a 39 -b1). Ou ainda: Se, porém, foi sempre verdadeiro dizer que é ou será, não poderá não ser ou não vir a ser (Aristóteles 1984, 18-b 8-13). A incompatibilidade referida é algo que se percebe quando da avaliação das frases assertóricas ${ }^{3}$ sobre o futuro, quer sejam verdadeiras agora, quer sejam falsas. Aplicando-se o mesmo princípio que guiou o grande filósofo nessas passagens, será difícil não ter uma conclusão contrária à contingência futura. Segundo muitos autores (e.g., Hugh 2015; Hintikka 1964; Mckim 1972; Waterlow 1982; Ackrill 1963; Frede 1970 e 1985, Craig 1988; Lukasiewicz 1930 e Putnam 1967), ${ }^{4}$ Aristóteles teria recusado atribuir valor de verdade a frases ou proposições que são sobre o futuro, e assim poderia evitar conclusões deterministas/fatalistas. Essa solução tem sido adotada na literatura ainda hoje, com diferentes estratégias (cf. Lucas 1989; Purtill 1988; Runzo 1981). ${ }^{5}$ O argumento que vamos estudar, contudo, parece chegar a conclusões opostas.

Apesar das diferenças de apresentação que Rietdijk, Putnam e Penrose têm, há uma dialética identificável que as versões clássicas partilham. "Versões clássicas" são aquelas em que o argumento recebe o nome de seus autores, naquilo que pode ser referido como a concepção Rietdijk-Putnam-Penrose. De todas as versões, há uma em que essa dialética é mais claramente exibida. Trata-se da versão de Putnam (Putnam 1967). Esse filósofo aceita, como dificilmente alguém bem informado poderia recusar, a relatividade especial. As divergências filosóficas sobre a relatividade especial dizem respeito a diferentes interpretações, algumas das quais não propõem a relatividade da simultaneidade. Essas, por conseguinte, não se preocupam com argumentos fatalistas ou deterministas. Putnam, entretanto, trabalha segundo interpretações clássicas da teoria. Podemos usar então a relatividade da simultaneidade como primeira premissa para o argumento a seguir:

1) A relatividade da simultaneidade é um fato.

2) Se 1, então não há, com respeito ao passado e ao futuro, nenhum privilégio ontológico a ser atribuído ao presente.

3) Se 2, então o eternismo é o caso; 
4) Se 3, então proposições assertóricas sobre qualquer fato (presente, passado ou futuro) têm valor de verdade;

5) Se 4, o futuro não é indeterminado.

Logo, há determinismo ou fatalismo.

Vejamos textualmente alguns desses passos. Em um momento particularmente importante, diz-nos Putnam, concluindo sua reflexão eternista:

Dado que o evento $x$ "está no futuro" relativamente ao meu sistema de coordenadas (...). Então, desde que tal evento obtenha a relação $R$ para com o seu-agora, a mesma relação será obtida pelo evento $x$, relativamente ao meu-agora. (...). Assim sendo, o evento $x$, o qual está no futuro relativamente ao meu sistema de coordenadas, é real agora! (Putnam 1967, p.243).

Na passagem acima, o principal é perceber que a relação $R$ ("ser real para...") é transitiva. Qualquer evento que seja real para mim tem de ser real para todos os observadores que estão nessa mesma relação comigo. Segundo a relatividade especial, se dois eventos são simultâneos em um sistema de coordenadas, digamos, a explosão de uma bomba em um teste atômico e o brilho de um "pulso de luz", oriundo da morte de uma estrela distante, não o serão para mim, desde que esteja em movimento em relação ao sistema de coordenadas no qual os eventos são percebidos (e legitimamente admitidos) como simultâneos. Mas, apesar desse fato, tais eventos são reais, ou seja, podem ser declarados existentes. São reais mas não pertencem ao meu presente. A relatividade da simultaneidade e sua alegada consequência eternista justificam a passagem para a bivalência, na dialética acima. O determinismo propriamente dito vem a seguir, inaugurado na secção do artigo cujo título é "A batalha espacial do amanhã".

A batalha espacial do amanhã, como Putnam diz, desafia Aristóteles (Aristoteles 1963) e a tese dos futuros contingentes. Segundo essa última, alguns fatos poderão ou não acontecer no futuro. Futuros contingentes são evitáveis, pois estão sujeitos a condicionantes. Na ausência dos condicionantes adequados, alguns fatos não acontecerão. Um exemplo possível é a própria batalha espacial. Se é contingente que haja uma batalha espacial no futuro, então poderei eventualmente evitá-la, e.g., poderei interceder pela paz entre os generais dispostos a lutar, com suas respectivas frotas estrelares. Putnam, quando comenta Aristóteles, parece adotar uma das interpretações disponíveis para a solução avançada pelo Estagirita. Como sabemos, nem todos os comentadores concordariam em dizer que Aristóteles recusa a bivalência. Putnam, entretanto, entende o autor como um defensor da tese semântica segundo a qual algumas proposições, nomeadamente sobre o futuro, não têm valor de verdade agora. O raciocínio expresso é, muitas vezes, uma condicional pela qual se recusa o consequente e, por modus tollens, o antecedente: 
i) Se toda proposição assertórica sobre o futuro tem valor de verdade agora, então tudo ocorre necessariamente (Fleck 1997, pp.12-3).

ii) Mas nem tudo ocorre necessariamente;

iii) Logo, nem toda proposição assertóricas sobre o futuro têm valor de verdade agora.

Vejamos como Putnam, na dialética do argumento que tentamos identificar, recusa a tese assumida para a argumentação de Aristóteles. Esse segundo momento do artigo é muito importante pois, efetivamente, o mesmo parece ter sido concebido com a finalidade de providenciar um argumento determinista. Putnam assume a relatividade da simultaneidade como um fato justificado pela teoria mais atual sobre o tempo. Um filósofo, para fins de se decidir por teorias rivais, deve estar bem informado sobre a ciência de seu tempo, na medida em que algumas teorias científicas podem ser relevantes para a consideração de algumas questões filosóficas. Aristóteles não tinha acesso a teorias que hoje são prometedoras para a solução de pelo menos alguns problemas metafísicos. A respeito das questões que temos investigado, Putnam é enfático:

Concluo que o problema acerca da realidade e determinidade de eventos futuros já está resolvido. Aliás, foi resolvido pela física e não pela filosofia. Temos aprendido que vivemos em um mundo tetradimensional, e não tridimensional, e que espaço e tempo - ou melhor, que as separações de tipo-espaço e as separações de tipo-tempo — são apenas dois aspectos de um contínuo singular (...) Em verdade, não creio que existam os problemas filosóficos de há muito sobre o tempo; há apenas o problema físico de determinar qual é a geografia exata que o contínuo tetradimensional em que habitamos tem (Putnam 1967, p.247).

O modus tollens a que Aristóteles teria recorrido tem a premissa "nem tudo ocorre necessariamente" presumida. Não havia evidência para não adotá-la, quando escreveu o livro nono das interpretações. Entretanto, quem aceitar a condicional expressa em "se toda proposição assertórica sobre o futuro tem valor de verdade agora, tudo ocorre por razões necessárias" e, ao mesmo tempo, aceitar a relatividade da simultaneidade, talvez tenha de reconhecer que a solução atribuível a Aristóteles é irrepetível:

$i^{*}$ Se toda proposição assertórica sobre o futuro tem valor de verdade agora, então tudo ocorre por razões necessárias.

$i i^{*}$ ) Toda proposição assertórica sobre o futuro têm valor de verdade agora:

iii*) Logo, tudo ocorre por razões necessárias.

A passagem do eternismo para alguma forma de determinismo, na dialética identificada, tem como base um modus ponens em tudo contrário ao que pensava Aris- 
tóteles, pelo menos segundo a interpretação de Putnam. O papel da relatividade da simultaneidade é apenas tornar crível, pela via mediada pelo eternismo, a tese de que todas as proposições, mesmo aquelas que são sobre o futuro, têm agora valor de verdade. O sucesso nesta tarefa supõe a primeira parte do argumento, na qual o eternismo fica provado e, por sua vez, a bivalência.

Rietdijk também adota o eternismo, uma vez que é bastante claro quanto a ser tetradimensionalista (Rietdijk 1966, p.341). Em verdade, o tetradimensionalismo é bastante difícil de compatibilizar com o presentismo. Os sentidos habituais em que "tetradimensionalismo" aparece podem ser aqui admitidos. No sentido em que Sider o usa, o termo ocorre como sinônimo para doutrina das partes temporais (Sider 2001, p.3). Entretanto, também é possível tê-lo referido a exemplo do que se tornou habitual entre filósofos australianos, i.e., para significar doutrinas-B sobre o tempo, também chamadas não-temporalizadas ou estáticas. Os dois sentidos dificilmente poderão ser desafiados enquanto eternistas; pelo menos não sem assumir uma posição pouco usual. ${ }^{6}$ Por essa razão, Rietdijk pode ser declarado como participando do esquema acima, nos passos dialéticos que vão de 1 a 3 . Os passos a seguir são menos claros, e se Rietdijk pode ser tratado nestes termos, então será necessário mostrar que razões deterministas podem ser reduzidas a razões semânticas ou equivalentes.

Vejamos exatamente onde o passo determinista é realizado:

Nós dizemos que um evento $P$ é (pré) determinado se para algum possível observador $W 1$ (isto é, para qualquer possível observador e até mesmo outras instâncias, i.e., instâncias físicas) que tem $P$ em seu futuro absoluto (isto é, que a futura parte de $W 1$ a perpassar todo o contínuo tetradridimensional pode, eventualmente, passar ao longo de $P$ ), pode-se pensar em um observador possível $W 2$ (ou: pode haver um observador $W 2$ ) que possa provar, em certo momento $T p$, que o observador $W 1$ não pode influenciar o evento $P$ de maneira arbitrária (por exemplo, impedir $P$ ) em qualquer momento, supondo que $W 1$ quisesse fazê-lo (Rietdijk 1966, p.342). ${ }^{7}$

Nessa passagem vemos que, apesar das diferenças de apresentação, as razões que os autores têm são equivalentes. O observador $W 2$ é capaz de saber, em posse das informações corretas sobre o sistema de coordenadas de $W 1$, quando um certo evento que pertence ao seu agora (agora de $W 2$ ) ocorrerá no futuro de $W 1 .{ }^{8} \mathrm{O}$ mais importante para nós é perceber que as razões epistémicas de Rietdijk podem ser equiparadas às razões semânticas de Putnam. Se $W 2$ pode prever algo no futuro de $W 1$, em posse de informações corretas sobre o sistema de coordenadas de $W 1$, então o fato sobre o qual se faz previsão, pertencente ao agora de $W 2$, será fundamento para qualquer proposição que o relate. Por isso, razões epistémicas em Rietdijk e razões semânticas em Putnam são equivalentes (pelo menos para fins de considerar a dialética do argumento). 
Razões igualmente equivalentes tem Penrose. Para este, o paradoxo de Andrômeda revela a impossibilidade de declarar qualquer incerteza sobre a decisão andromediana de invadir a Terra. No pitoresco exemplo recorrido pelo autor, uma nave andromediana invade o planeta, o que é percebido em um sistema de coordenadas, mas em outro não. Seu veredicto é a respeito da deliberação andromediana, que estaria determinada, uma vez que é inevitável no futuro do sistema de coordenadas em que ainda não ocorreu: "Se para alguém é verdade que a decisão foi tomada, então não pode realmente haver incerteza quanto a isso. O lançamento da nave espacial é inevitável" (Penrose 1989, p.303).

Ora, a certeza que se pode ter a respeito de um evento que é presente em um sistema de coordenadas e futuro em outro é precisamente o fato relevante no argumento de Rietdijk. Logo, não há razão para não aplicar a Penrose a mesma dialética dos autores que o antecedem. ${ }^{9}$

\section{O Fatalismo lógico-semântico}

O fatalismo lógico, como muitas vezes é chamado, é a doutrina segundo a qual há certa incompatibilidade entre princípios aceites em lógicas clássicas (a bivalência e o terceiro excluído), a contingência para o futuro e o livre arbítrio. Em alguns casos, quando o termo "fatalismo" é invocado, o que se quer é evidenciar essa doutrina. Inwagen é um exemplo de autor que reserva o termo "fatalismo" para referir condições lógico-conceptuais para a necessidade de tudo (Inwagen 1986, p.23). ${ }^{10}$ Mas será que tudo não poderá ser necessário por outras razões e, apesar disso, a doutrina do fatalismo estar contemplada? Haveria, por exemplo, um fatalismo por razões deterministas? Taylor e outros pensam ${ }^{11}$ que sim:

O determinismo, recorde-se, é a tese de que todos os eventos são resultados inevitáveis porque têm causas. Existe uma tentativa de distinguir fatalismo de determinismo por dizer que, de acordo com o fatalismo, certos eventos são inevitáveis não importa o quê; ou, em outras palavras, independentemente de suas causas... O fatalismo é a crença de que tudo o que ocorre é inevitável. Essa é uma maneira de se expressar claramente sobre a doutrina, e nos da a base daquela atitude de calma e aceitação que o fatalista pensa poder abraçar, corretamente. Aquele que subscreve a doutrina segundo a qual o comportamento humano é causalmente determinado é, então, um tipo de fatalista, ou pelo menos deveria sê-lo, se quiser ser consistente (Taylor 2015, p.42). ${ }^{12}$

A diferença entre fatalismo e determinismo diz respeito às razões de necessidade apontadas por ambas. Via de regra, o fatalismo não recorre a razões nomológicas. Normalmente, o determinismo é mencionado como uma tese envolvendo algum tipo 
de necessidade na relação entre partes em um mesmo espaço-tempo. Uma maneira de entender como essa necessidade pode ser possível é pensar no papel das leis da natureza na organização do mundo. Se determinista, a forma como o mundo é agora fixa a maneira como as coisas podem ser no futuro ou passado (cf. Butterfield 1989, pp.10-1). O fatalismo, diferentemente, não supõe nenhum tipo de relação especial, mediada por leis (por exemplo as leis da natureza) para atestar a necessidade de tudo. A conclusão filosófica pelo fatalismo acompanha razões lógico-semânticas, mas não exclui outras razões, apenas não as especifica. Apesar dessa diferença, há coincidência sobre o que é realmente importante: a necessidade relativamente ao futuro e uma alegada incompatibilidade com o livre-arbítrio. ${ }^{13}$

Naturalmente, ao dizer que o futuro é necessário porque as leis da natureza o implicam, não estamos a subscrever a tese de que o futuro é metafisicamente necessário. Tampouco dizer que o determinismo e o fatalismo têm uma certa relação, como o fizemos, sugere essa implicação. A relação entre determinismo e fatalismo não está dependente de nenhuma confusão entre modalidades, i.e., qualquer sentido atribuível à palavra "necessário" (necessidade lógica, necessidade nomológica, etc.), desde que suficientemente forte para cumprir com o requisito da inevitabilidade de tudo, poderá ser admitido como fatalista. Portanto, a necessidade metafísica não tem de estar implicada. O imprescindível é ter conhecimento das diferentes razões pelas quais essas teses, o determinismo e o fatalismo, são defendidas.

Na próxima secção, pretendo mostrar que o argumento de Rietdijk, Putnam e Penrose pode ser considerado fatalista.

\section{O fatalismo relativístico}

Quando identificamos a dialética do argumento de Rietdijk, Putnam e Penrose, identificamos o papel atribuído à relatividade da simultaneidade. Era o de justificar o antecedente da condicional segundo a qual tudo ocorre necessariamente: se toda proposição assertórica sobre o futuro tem agora valor de verdade, então tudo ocorre necessariamente. Vimos que, na dialética em questão, os autores deduzem uma tese metafísica que implica a tese semântica da bivalência. O eternismo é essa tese metafísica. As questões então passam a ser: o que a condicional significa? Tem de ser ela mesma aceita? A resposta à segunda depende da interpretação que adotamos sobre a primeira. Isto é, aceitar que tudo ocorre por necessidade dependerá da interpretação da condicional "Se todas as proposições assertórica sobre o futuro têm valor de verdade agora, então tudo ocorre por razões necessárias".

As duas interpretações mais comuns são: ou o operador de necessidade tem como âmbito a condicional "se a frase ' $P$ ' é verdadeira, então $P$ "; ou então tem como âmbito o consequente da mesma; ou seja, a necessidade recai sobre $P$. Usualmente, a 
diferença em questão é apresentada como necessitas consequentiae e necessitas consequentiis:

Necessitas consequentiae:

Necessariamente, se a frase ' $P$ ' é verdadeira, então $P$ é o caso.

$\square\left(\mathrm{V}^{\prime} P^{\prime} \rightarrow P\right)$.

Necessitas consequentiis:

Se a frase 'P' é verdadeira, então $P$ é necessário.

$\left(\mathrm{V}^{\prime} P^{\prime} \rightarrow \square P\right)$.

O fatalismo lógico surge como problema a partir da afirmação da necessidade da consequente $P$, admitida como consequência da verdade da frase ' $P$ '. Se a dialética extraída desde Putnam for acompanhada, a passagem do eternismo para a bivalência é um passo fundamentado, e a passagem da bivalência para o fatalismo pode se dar de tal forma que se conceba a necessidade da consequente ( $\mathrm{V}^{\prime} P^{\prime} \rightarrow \square P$ ).

Mas como poderá também ser defendido que a necessidade da consequência $\square\left({ }^{\prime} V\right.$ 'P $\left.\rightarrow P\right)$ - tem implicações fatalistas? Quando perguntamos pelas razões para a verdade de ' $P$ ', sendo essa uma frase sobre o futuro, o que encontramos como resposta?

Se ' $P$ 'é uma frase sobre o futuro e é verdadeira agora, qual é a razão em função da qual ' $P$ ' é verdadeira?

A resposta não será surpreendente: 'P' é verdadeira se o determinismo for o caso. Se considerarmos a tese de que o determinismo satisfaz critérios fatalistas, ${ }^{14}$ como nos diz Taylor (Taylor 2015), a passagem da bivalência para o fatalismo, na dialética apresentada, pode ser interpretada como determinista, i.e., $P$ é um fato futuro inevitável porque está determinado pelas conexões entre partes espaço-temporais em um mesmo mundo. O passo aqui tem a seguinte direção: se há valor de verdade para uma frase futura deve haver uma razão para isso. Como o determinismo é uma razão suficiente, essa tese poderá ser sugerida para explicar como podemos fundamentar agora verdades sobre o futuro.

Mas o fatalista teria ainda uma terceira possibilidade de vencer. Podemos fazer uso de um princípio antigo, segundo o qual o passado é necessário, para concluir pelo fatalismo. Existem muitas maneiras diferentes de formular o princípio da necessidade do passado. Todas elas, no entanto, afirmam que o passado é necessário uma vez que já aconteceu. Isso significa que fatos no passado que poderiam não ter ocorrido, supostamente não-necessários, uma vez ocorridos, tornam-se necessários doravante. Vejamos como podemos construir uma versão do fatalismo usando esse princípio.

Se a batalha de Hastings ocorreu precisamente em 1066, não há nada que possamos fazer agora (nem haverá amanhã) para torná-la um evento posterior (cf. Priest 
2000, p.45). E não o podemos porque, uma vez ocorrida a batalha em 1066, é necessário agora que tenha ocorrido nessa data. Assim, se $H$ é um proposição sobre o passado que expressa a ocorrência da batalha em 1066, então $V H \rightarrow \square V H$ é o caso, pois todas as verdades sobre o passado são verdades necessárias. A conclusão fatalista se seguiria do fato de que a frase $H$, proferida muito tempo antes de 1066, por exemplo, no ano 1000, seria já verdadeira (Priest 2000, p.45). Como em 1066 era impossível alterar o passado, então a batalha era necessária já no ano 1000, inevitável e, portanto, o fatalismo seria verdadeiro.

Agora podemos considerar uma frase sobre o futuro, como, por exemplo: "haverá um prémio Nobel brasileiro em 2020". Suponhamos que essa frase seja dita em 2017. Sendo uma sobre o futuro, porém, enunciada no passado, a atribuição do princípio da necessidade do passado a ela se aplica agora, quando verdadeira ou falsa, i.e., se verdadeira, é necessariamente verdadeira, se falsa, necessariamente falsa. Os demais passos do argumento também obtêm e, nesse cenário, se o argumento for bem sucedido, teremos um bom exemplo de fatalismo. Como Priest notou (Priest 2000, p.45), pouco importa que ninguém tenha proferido uma frase dessas, uma vez que é uma frase possível. Um exemplo igual poderá ser sempre criado com a simples enunciação de uma frase declarativa sobre o futuro. Como é verdade que poderíamos ter uma frase assim dita em qualquer tempo sobre qualquer evento, o argumento se aplica a qualquer fato que ocorreu, ocorre ou ocorrerá.

Assim, apesar de vários passos intermédios, teríamos uma implicação da relatividade especial para o fatalismo, embora o argumento não seja outro que não o argumento clássico de Aristóteles (segundo uma interpretação possível), Diodoro Crono (284 Ac) e outros. ${ }^{15}$ Em última análise, a forma mais promissora de argumentar pelo fatalismo lógico seria recorrer ao princípio da necessidade do passado. Se a relatividade especial implica o eternismo (via relatividade da simultaneidade), então o fatalismo se seguiria da defesa de que o eternismo implica tratar todos os fatos, em qualquer ponto do espaço-tempo, como se a eles se aplicassem a mesma necessidade que se pensava reservada a fatos passados.

\section{Refutação do fatalismo relativístico}

Resta rejeitar o fatalismo relativístico. O faremos em três momentos. No primeiro, recusaremos o fatalismo lógico simpliciter, usando para isso a perspectiva segundo a qual esse raciocínio incorre em falácia modal. No segundo, rejeitaremos o fatalismo como consequência de um suposto determinismo, o qual não parece ter condições de prova via argumento em questão. Finalmente, exploraremos uma versão mais convincente do fatalismo lógico, a qual, não sendo falaciosa, exige-nos uma adequada contrapartida. A resposta será o ockhamismo, especialmente uma certa versão dessa doutrina. 
Segundo Priest (Priest 2000), Iacona (Iacona 2007), Haack (Haack1998) e muitos outros, extrair $\left(V^{\prime} P^{\prime} \rightarrow \square P\right.$ ) da necessidade da consequência é uma falácia modal. Gostaríamos de adotar essa opinião, a qual parece seguir aquilo que podemos considerar mais assertivo sobre o problema dos futuros contingentes: a atitude de rejeitar o argumento lógico-semântico sem abandonar a bivalência. Alegadamente, extrair a necessidade da consequente $P$ da verdade de ' $P$ ' é infundado. Muitos são os autores em quem podemos nos apoiar para oferecer essa resposta. Haack, por exemplo, apresenta uma excelente explicação a respeito do equivoco modal:

Penso que o argumento é invalido porque depende de uma falácia modal, a falácia de argumentar a partir de: Necessariamente, se é agora verdadeiro [falso] que vou estar em Varsóvia ao meio-dia de 21 de dezembro do próximo ano, então eu [não] vou estar em Varsóvia ao meio-dia de 21 de dezembro do próximo ano,

O que é, claro, verdadeiro, para:

Se é agora verdadeiro [falso] que eu vou estar em Varsóvia ao meio-dia de 21 de dezembro do próximo ano, então necessariamente eu [não] vou estar em Varsóvia ao meio-dia de 21 de dezembro do próximo ano, (...) Se não esta obvio que isto seja uma falácia, consideremos esta instância que claramente não preserva a verdade: $L((p \& q) \rightarrow p$ ), $\log$ o $(p \& q) \rightarrow L p$ (Haack 1998, pp.275-6).

Em verdade, a tese fatalista é responsável por causar algum desconforto. Mas esse desconforto não é o mais relevante para entender a objeção da autora: "Se estou certa a respeito disto, o fatalismo não se segue da bivalência, assim, mesmo que o fatalismo seja uma tese inaceitável, não há necessidade de rejeitar a bivalência por causa disso" (Haack 1998, p.276). O mais relevante é o caráter inválido do argumento que compromete a bivalência com o fatalismo, e não a estranheza ou desconforto que a tese fatalista nos causa.

Com o argumento de Rietdijk, Putnam e Penrose passa-se o mesmo. A passagem da relatividade da simultaneidade para o eternismo dá à bivalência uma prevalência. Efetivamente, se o eternismo é o caso, proposições sobre o futuro têm agora valor de verdade. Mas a conclusão pelo fatalismo não deve receber mais atenção do que a refutação acima, uma vez que a via pela qual se comete o equivoco é a mesma. Há sempre o perigo de incorrer em falácia modal com a argumentação puramente lógica para o fatalismo, mesmo que a bivalência seja adotada por razões filosóficas (eternismo), e mesmo que essas razões recorram a teorias científicas (relatividade especial).

A opinião fatalista, entretanto, tem os seus defensores ainda hoje, os quais parecem convencidos de que teorias sobre o tempo de um certo tipo são fatalistas. Levin 
(Levin 2007), por exemplo, menciona Lockwood (Lockwood 2005) e Rietdijk (Rietdijk 1966), os quais teriam aceitado o fatalismo relativístico. ${ }^{16} \mathrm{Em}$ tese, basta uma doutrina que satisfaça a descrição teorética- $\mathrm{B}^{17}$ sobre o tempo para que se possa contemplar aquilo que o autor chama "fatalismo de série-B". Se os autores do argumento são fatalistas em um sentido clássico, ou seja, fatalistas que argumentam pela via lógico-semântica, então estão sujeitos à acusação de falácia modal. Mas há uma outra hipótese.

Podemos atribuir ao argumento uma ameaça determinista. O argumento assim balizado ganha outra viabilidade, uma vez que é compatível com $\square\left(V^{\prime} P^{\prime} \rightarrow P\right)$. Tratase de uma interpretação pouco usual que gostaríamos de propor para a antiga problemática do fatalismo lógico: as razões lógicas da argumentação pelo fatalismo implicam razões de natureza determinista. Ela presume apenas certa relação entre teses metafísicas como o determinismo e teses semânticas como a bivalência, tal que a primeira se configura em fundamento adequado para a segunda. Entretanto, mostraremos que esse caminho não é adequado para argumentar pelo fatalismo relativístico, uma vez que o determinismo é apenas razão suficiente para assumir a tese semântica da bivalência, não sendo, contudo, necessário. O eternismo é igualmente uma condição suficiente, e está inegavelmente envolvido na argumentação dos autores, concedendo-nos a razão de que precisamos. O argumento determinista funcionaria caso houvesse uma implicação entre eternismo e determinismo. Mas não há essa implicação, pelo menos se o determinismo for tomado na acepção clássica (determinismo causal, baseado em relações normalmente referidas como regimentadas por necessidade legiforme), muito embora haja quem argumente em favor de um suposto determinismo ontológico como consequência, como por exemplo Shanks (Shanks 1994). Para além de invocar uma noção obscura - "determinismo ontológico" - Shanks esbarra em soluções clássicas como o ockhamismo, que veremos a seguir. Se correto, o ockhamismo permite tratar o eternismo como compatível com a existência de contingência, negando a perspectiva de um possível determinismo ontológico.

Sem implicações deterministas imediatas, a necessidade da consequência não implica a necessidade do consequente. A ameaça determinista se constituiria na alegação de que o determinismo (em qualquer acepção) seria verdadeiro, se essa fosse a única razão para fundamentar $V^{\prime} P$ ', em que ' $P$ ' é uma frase sobre o futuro. Quem aceitar o eternismo como implicado pela relatividade tem já uma razão metafísica capaz de justificar a verdade de qualquer frase sobre o futuro. Logo, se aceitamos a necessidade do consequente $\square\left(V^{\prime} P\right.$ ' $\rightarrow P$ ) porque aceitamos a verdade de ' $P$ ', temos por satisfeita a condição de verdade para frases dessas. O eternismo e o determinismo, separadamente, são razões suficientes para fundamentar a bivalência. Nenhuma das duas teses se configura em razão necessária.

Sendo o determinismo uma tese sobre relações de necessitação entre fatias (slices) 
de espaço-tempo, ${ }^{18}$ cumpre se perguntar: há alguma razão para achar que partes em um mundo eternista têm entre si essas relações? A resposta a essa questão é não. $\mathrm{O}$ eternismo não nos diz nada sobre a relação entre partes em um mesmo espaçotempo. Diz apenas que certos fatos existem, logo, as proposições ou frases sobre eles são passíveis de verdade ou falsidade. Mas nada faz crer que, por terem os fatos uma certa configuração, esta configuração é a única que lhes era possível, dadas, por exemplo, as leis da natureza. Se a maneira como traçamos a dialética está correta, tendo em vista as razões que são possíveis extrair de supostos fatos científicos (como a relatividade da simultaneidade), então a via fatalista que supõe a necessidade da consequência é apenas um non sequitur. Nada no argumento nos diz como devem ser as relações entre partes em um mesmo espaço-tempo, ainda que nosso mundo seja eternista.

Relativamente à versão do argumento que usa a necessidade do passado para fundamentar o fatalismo, podemos responder por adotar alguma versão do ockhamismo. Enquanto solução para o problema dos futuros contingentes, o ockhamismo tem sido muito estudado e adotado, em diferentes versões (cf. Marilyn Adams 1967; Plantinga 1986; Rea e Finch 2008; Rosenkranz 2012). Segundo Adams, a necessidade do passado não é um princípio válido para todos os fatos passados, mas apenas para alguns, tecnicamente chamadas "fatos duros" (hard facts). Fatos duros são fatos que não dependem de nada no futuro para serem verdadeiros, e.g., "Houve uma crise financeira na Europa em 2008", "A morte de Napoleão foi em cinco de maio de 1821", etc. Proposições como, por exemplo, "Nasceu ontem o maior filósofo do século XXI", ou "A crise financeira de 2008 será a maior de todas", diferentemente, se relacionam com o futuro de forma tal que, para serem verdadeiras, algo no futuro tem de ser coincidente com aquilo que dizem. São, no vocabulário filosófico corrente, "fatos moles" (soft facts). Se o princípio da necessidade do passado for desafiado ou restringido apenas a fatos duros, perde-se no argumento lógico-semântico pelo fatalismo a premissa fundamental de que aquilo que foi dito no passado sobre o hoje, quando verdadeiro, é necessariamente verdadeiro.

Embora haja muita crítica sobre a distinção que desafia a necessidade do passado, uma serie de melhorias foi sendo acrescentada, de modo a tornar a distinção entre fatos duros e fatos moles algo mais inteligível, ou apenas mais simples. Plantinga (1986) esclarece que a necessidade do passado não se aplica a todos os fatos. Os fatos duros, embora necessários, são apenas "acidentalmente necessários", uma vez que sua necessidade só se segue de terem já ocorrido, sendo a sua primeira ocorrência contingente, no sentido de que poderiam nunca ter acontecido. Aquelas verdades dependentes do futuro, porém, não se teriam realizado caso um certo estado de coisas não se atualizasse no futuro. A essas não se atribui nenhuma necessidade. ${ }^{19}$ Segundo esse autor, alguns fatos (aqueles que dependem daquilo que estou a realizar agora) poderiam ser modificados num sentido contrafactual. Por exemplo, a minha decisão 
agora tornou verdadeira ou falsa uma proposição dita no passado, mas se a minha decisão tivesse sido outra, o valor de verdade da mesma teria sido, também, diferente.

Por fim, a solução ockhamista inclui ainda uma outra componente. Nos modelos que incluem essa solução, os autores distinguem os fatos futuros sobre os quais há agora verdade com uma "fina linha vermelha" (Belnap e Green 1994) ${ }^{20} \mathrm{~A}$ "fina linha vermelha" abrange um futuro que é chamado de "atual"; porém, esse futuro, apesar de atual, pode ser contingente. A atualidade de um futuro contingente, assinalada no modelo ockhamista, será representada em termos de "existência não-temporalizada", pelo menos na versão que iremos adotar. Essa solução foi usada por Rea e Finch (Rea e Finch 2008), e consiste em unir o ockhamismo e o eternismo em um corpus orgânico. Se essa ideia pode se aplicar ao espaço-tempo tetradimensional e eternista, então podemos evitar a versão mais promissora da argumentação pelo fatalismo lógico, de que o fatalismo relativístico seria um caso particular.

\section{Conclusão}

A conclusão deste artigo é parcialmente desfavorável ao argumento de Rietdijk, Putnam e Penrose. Só não o é totalmente pois, em alguns casos, uma versão do argumento tem sido usada por filósofos que pretendem apenas o eternismo, sem afirmações deterministas ou fatalistas. Esse é o caso, por exemplo, de autores como Petkov, (Petkov 2006), Petersen e Silberstein (Peterson e Silberstein 2010), Rakić (Rakić 1997) e Gödel, (Gödel 1949).

A conclusão de que o argumento falha se dá após a consideração de três respostas possíveis, duas baseadas na literatura e uma original. O argumento tem uma dialética que prova o eternismo, além de oferecer-nos razões metafísicas para adotar o princípio da bivalência. Essa dialética, entrementes, ou é usada para extrair a necessidade da consequência, ou é usada para extrair a necessidade do consequente. No segundo caso é uma falácia modal, no primeiro é compatível com o determinismo, mas não o prova. Qualquer determinismo assente é, nesse caso, não mais do que um non sequitur. Essa interpretação dos futuros contingentes, pelo menos enquanto resposta ao fatalismo relativístico, é uma contribuição original deste artigo ao debate. Demonstramos com ela que o argumento falha em mostrar que o determinismo está implicado, uma vez que falta provar que um mundo eternista tem um certo tipo de relação de necessitação entre partes espaço-temporais. Por fim, se há uma versão do ockhamismo que usa o eternismo para evitar o fatalismo lógico, então deve haver também uma solução inspirada no ockhamismo para a versão mais interessante do fatalismo relativístico. Neste caso, a razão para evitar ceder ao fatalismo relativístico é apenas a existência de boas replicas aplicáveis, embora o argumento seja válido e tenha méritos. 


\section{Referências}

Aristóteles. 1984. The Complete Works of Aristotle, Opera, ed. Academia Regia Borussia, Berlim, W. de Gruyter. The Revised Oxford Translation, ed. J. Barnes. Princeton: Princeton University Press.

Aristotle.1963. Categories and De Interpretatione. J. H. Ackrill (trans.). Oxford: Clarendon Press.

Adams, M. 1967. Is the Existence of God a 'Hard' Fact? The Philosophical Review 76(4): 492503.

Anscombe, G. E. M. 1956. Aristotle and the Sea Battle. Mind 65(257): 1-15.

Butterfield, J. 1989. The Hole Truth. The British Journal for the Philosophy of Science 40(1): $1-28$.

Belnap, N.; Green, E. M. 1994. Indeterminism and the thin red line. Philosophical Perspectives, Logic and Language 8: 365-88.

Craig, W. 1988. The Problem of Divine Foreknowledge and Future Contingents from Aristotle to Suarez. Leiden: E. J. Brill.

Earman, J. 1986. A Primer On Determinism. Netherlands: Springer.

Fleck, F. P. A. 1997. O problema dos futuros contingentes. Porto Alegre: EDIPUCRS.

Frede, D. 1970. Aristoteles und die "Seeschlacht". Göttingen, Vandenhoeck \& Ruprecht.

- 1985. The Sea-Battle Reconsidered: A Defense of the Traditional Interpretation. Oxford Studies in Ancient Philosophy 8: 31-87.

Gallina, F; Spolaore, E G. 2016. Futuri Contingenti, In: APhEx Portale Italiano de Filosofia Analitica, Giornale di Filosofia: http://www.aphex.it/public/file/Content20160203 APhEx13-2016TemiFuturiContingentiGallina-Spolaor.pdf. Consultado em 27/02/2019.

Gödel, K. 2006. Uma nota acerca das relações entre a teoria da relatividade e a filosofia idealista. Revista Brasileira de Ensino de Física 28(4): 521-24.

Haslanger, S. 2003. Persistence through Time. In: M. J. Loux; D. W. Zimmerman (ed.) The Oxford Handbook of Metaphysics, pp.315-54. Oxford University Press.

Haack, I. 1998. Filosofia das Lógicas. São Paulo: Editora UNESP.

Hintikka, J. 1964. The Once and the Future Sea Fight. Philosophical Review 73: 461-92.

Hugh, R. 2015. Fatalism. In: Edward N. Zalta (ed.) The Stanford Encyclopedia of Philosophy (Summer 2015 Edition). http://plato.stanford.edu/archives/sum2015/entries/fatalism. Consultado em 06/12/2015.

Iacoma, A. 2007. Future Contingents and Aristotle's Fantasy. Critica: Revista Hispanoamericana de Filosofia 39(117): 45-60.

Inwagen, I. 1986. An Essay of Free Will. Oxford: Oxford University Press.

Kyle, J. D. 2009. God, Fatalism, and Temporal Ontology. Religious Studies 45(4): 435-54.

Lucas. J. R. 1989. The Future: An Essay on God, Temporality, and Truth. London: Blackwell.

Lukasiewicz, J. 1930. Philsophical Remarks on Many-Valued Systems of Propositional Logic. In: Storrs McCall (ed.) Polish Logic pp.40-65. Oxford: Clarendon Press.

Lockwood, M. 2005. The Labirint of time: introducing the Universe. Oxford: Oxford University Press.

Levin, M. 2007. Compatibilism and Special Relativity. The Journal of Philosophy 104(9): 43363. 
Marques, J.M. 2017, A relatividade da simultaneidade e suas possíveis consequências filosóficas. Principia: an international journal of epistemology 21(3): 391-409.

McTaggart. J. E. M. 1908. The Unreality of Time. Mind 18: 457-84.

McKjm, V. R. 1972. Fatalism and the Future: Aristotle's Way Out. Review of Metaphysics 25(1): 80-111.

Peterson, D.; Silberstein, M. 2010. Relativity of Simultaneity an Eternalism: in Defense of the Block Universe. In: V. Petkov (ed.) Space, time and spacetime, pp.209-37. Heidelberg: Springer.

Penrose, R. 1989. The Emperor's New Mind: Concerning Computers, Minds, and Laws of Physics. New York and Oxford: Oxford University Press.

Petkov, V. 2006. Is There an Alternative to the Block Universe View? In: D. Dieks; M. Redei (eds.) The Ontology of Spacetime, Series on the Philosophy and Foundations of Physics, pp.207-28. Amsterd: Elsevier.

Putnam, H. 1967. Time and Physical Geometry. Journal of Philosophy 64(8): 240-47.

Plantinga, A. 1986. Ockham's Way Out. Faith and Philosophy 3: 239-40.

Priest, G. 2000. Logic, A Very Short Introduction. Oxford: Oxford University Press.

Rakić, N. 1997. Past, Present, Future, and Special Relativity. The British Journal for the Philosophy of Science 48(2): 257-80.

Purtill, R. 1988. Fatalism and the Omnitemporality of Truth. Faith and Philosophy 5(2): 18592.

Rosenkranz, S. 2012. In Defence of Ockhamism. Philosophia 40(3): 617-31.

Rietdijk, C. W. 1966. A Rigorous Proof of Determinism Derived from the Special Theory of Relativity. Philosophy of Science 33(4): 341-4.

Rea, M.; Finch, A. 2008. Presentism and Ocham's Way Out. In: Jonathan L. Kvanvig (ed.) Oxford Studies in Philosophy of Religion, pp.1-17.

Runzo. J. 1981. Omniscience and Freedom for Evil. International Journal for Philosophy of Religion 12(3): 131-47.

Savitt, S. 2014. Being and Becoming in Modern Physics. In: Edward N. Zalta (ed.) The Stanford Encyclopedia of Philosophy, Summer 2014 Edition. http://plato.stanford.edu/archives/ sum2014/entries/spacetime-bebecome/. Consultado em 27112015.

Shanks, N. 1994. Time, Physics and Freedom. Metaphilosophy 25(1): 45-59.

Schlick, M. 1931. Die Kausalität in der gegenwärtigen Physik. Die Naturwissenschaften 19(7): 145-62.

Sider, T. 2001. Four-Dimensionalism, An Ontology of Persistence and Time. Oxford: Clarendon Press.

Taylor, R. 2015. Fate. In: J. M. Fischer; P. Todd (eds.) Freedon, Fatalism and foreknowledge. Oxford: Oxford University Press.

Thomason, R. 1970. Indeterminist time and truth value gaps. Theoria 36: 264-81.

- 1981. Deontic Logic as Founded on Tense Logic. In: R. Hilpinen (ed.) New Studies in Deontic Logic, pp.165-76. Dordrecht: D. Reidel.

- 1984. Combinations of Tense and Modality. Handbook of Philosophical Logic. Vol. II. Dordrecht: D. Reidel.

Torretti, R. 1983. Relativity and Geometry. Oxford, New York, Toronto, Sydney, Paris, Frankfurt: Pergamon Press.

Waterlow, S. 1982. Passage and Possibility. Oxford: Clarendon Press. 
Whitaker, C. W. A. 1996. Aristotle's de Interpretatione. Oxford: Clarendon Press.

\section{Notas}

${ }^{1}$ Há um argumento filosófico que considera a relatividade restrita, por Gödel, em 1949. Trata-se de um argumento que precede Rietdijk temporalmente. Entretanto, tal argumento não pretende provar nenhuma tese determinista ou fatalista, ao contrário dos autores de que vamos nos ocupar.

${ }^{2} \mathrm{O}$ mesmo para o princípio do terceiro excluído.

${ }^{3}$ Para o propósito desse artigo, não é relevante distinguir proposições de frases, embora sejam coisas diferentes.

${ }^{4}$ Para uma consideração diferente sobre a interpretação aristotélica, consultar, por exemplo, Whitaker (Whitaker 1996) e Anscombe (Anscombe 1956).

${ }^{5}$ Veja-se, por exemplo, estratégias supervaloracionistas, como a de Thomason (1970; 1981; 1984). Para estratégias como essa, o princípio da bivalência é parcialmente válido. O Mundo é indeterminista quando há muitas situações contrafactuais compatíveis com o presente, algumas das quais são fundamento para a verdade, outras para a falsidade. O princípio clássico da bivalência é válido para cada uma dessas circunstâncias tomadas individualmente, mas o todo (a árvore do tempo - branching time —como um todo) não admite bivalência.

${ }^{6}$ Para uma defesa sobre a descontinuidade entre doutrina das partes temporais e eternismo, ver Haslanger (Haslanger 2003).

${ }^{7}$ Tradução Minha.

${ }^{8}$ Embora isso seja possível em situações previstas pela relatividade especial, estas resoluções são meras possibilidades teóricas, uma vez que a relatividade da simultaneidade não faz parte da nossa experiência cotidiana. A física newtoniana é útil, pois, nas interações a que estamos sujeitos, não há diferença significativa entre eventos percebidos em diferentes sistemas de coordenadas.

${ }^{9}$ Para uma apresentação completa de cada versão deste argumento, ver Marques (2017).

${ }^{10}$ Schlick (1931) preferia o termo "determinismo lógico" para a tese que hoje conhecemos como fatalismo, demarcando diferenças para o chamado "determinismo causal". O leitor irá encontrar ainda hoje muitos autores que usam essa expressão para essa mesma doutrina.

${ }^{11}$ Recentemente, esse mesmo ponto foi notado Francesco Gallina e Guiseppe Spolaore (2016).

${ }^{12}$ Tradução minha.

${ }^{13}$ Salvo hipóteses compatibilistas.

${ }^{14}$ Quais sejam: ausência de livre-arbítrio, inevitabilidade para o futuro, etc.

${ }^{15}$ Não se ignora que entre esses (e outros) autores há diferenças de apresentação e de interpretação, acerca das teses e argumentos. Entretanto, todas as versões dos argumentos desses autores providenciam um argumento lógico semântico para o fatalismo.

${ }^{16}$ Levin é, nesse artigo, um defensor do compatibilismo, i.e., o fatalismo relativístico seria compatível com o livre-arbítrio.

${ }^{17}$ Neste contexto, "serie-B" é usado para referir teorias não-temporalizadas sobre o tempo, e como sinônimo para eternismo. A série-B foi proposta por McTaggart pela primeira vez em 
1908, e ordena os eventos numa linha cujas relações que mantém entre si são de simultaneidade, anterioridade e sucessão.

${ }^{18}$ Habitualmente, as relações entre partes em um mundo determinista têm sido pensadas como legiformes. Entretanto, não é preciso ter essa noção em mente. Shanks implica o determinismo de um modelo eternista em especial, mas a noção que evoca é outra (Shanks 1994, p.54). Aliás, um ponto relevante do argumento de Shanks é precisamente este: o libertista que se ampara em partes de teorias científicas para sustentar o seu não-determinismo pode estar enganado. Isso porque, se há outras noções de determinismo consequentes com o universo em bloco, então poderá não ser suficiente que o mundo tenha, por exemplo, leis da natureza que não garantem o determinismo.

${ }^{19}$ Muitas vezes a esse tipo de necessidade, reservada apenas a alguns fatos passados (fatos duros), atribui-se o nome de necessidade histórica, necessidade acidental ou ainda necessidade temporal.

${ }^{20} \mathrm{~A}$ "fina linha vermelha", do inglês thin red line, foi proposta por Belnap e Green (Belnap e Green 1994) para referir um futuro atual dentre muitos que são meras possibilidades. 